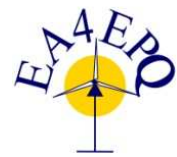

International Conference on Renewable Energies and Power Quality (ICREPQ'19) Tenerife (Spain), $10^{\text {th }}$ to $12^{\text {th }}$ April, 2019

Renewable Energy and Power Quality. Fournal (RE\&PQJ)

ISSN 2172-038 X, Volume No.17, July 2019

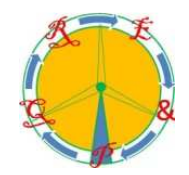

\title{
Mediterranean - Dead Sea Channel for Preserving Dead Sea Level and Increasing Solar Energy Production
}

\author{
S. Lyneikin ${ }^{1}$, A. Averbukh ${ }^{2}$, M. Averbukh ${ }^{3}$ and A. Zinger ${ }^{4}$ \\ ${ }^{1}$ Department of Mechanical Engineering and Mechatronics \\ Ariel University, 4077625, Ariel, (Israel) \\ Phone/Fax number: +972 522394481, e-mail: simonl@ariel.ac.il \\ ${ }^{2}$ Department of Public Relations \\ Ariel University, 4077625, Ariel, (Israel) \\ Phone/Fax number: +972 507898991, e-mail: alexanderav@ariel.ac.il \\ ${ }^{3}$ Department of Electric/Electronic Engineering \\ Ariel University, 4077625, Ariel, (Israel) \\ Phone/Fax number: +972 528814120, e-mail: mosheav@ariel.ac.il \\ ${ }^{4}$ Department of Electric/Electronic Engineering \\ Ariel University, 4077625, Ariel, (Israel) \\ Phone/Fax number: +972 528814120, e-mail: zingeralon@gmail.com
}

\begin{abstract}
Currently, for the Israeli society there exist three closely connected challenges whose solution will be able to have a great influence on the future prosperity, social and economic aspects of life and to ensure its continuation as an independent and well-developed country. These challenges are the requirements of a sufficient water supply, energy production and environmental protection. Environmental protection refers to the most difficult global problems among which are a rapid decrease in the Dead Sea level, as well as the irreversible and very dangerous increase in salination of Mediterranean Sea water in the offshore zone. The solution includes the construction of a large amount of PV facilities in the Negev area, a channel from the Mediterranean Sea to the Judean Heights area with installation of desalination plants. Finally, the cascade of hydropower electrical stations in the descent from the Judean heights to the Dead Sea. The turbines of hydropower stations will apply the brine from the collecting pools for electricity production and will direct it after use to the Dead Sea.

This article represents preliminary analysis of such a project and provides estimation of its probable contribution on energy and water production as well as of its environmental impact.
\end{abstract}

\section{Key words}

Renewable energies, water supply, channel Mediterranean -Dead Sea.

\section{Introduction}

The present and future progress in Israeli economy are determined by three closely related problems whose successful solution will have a great influence on the country development, and to ensure its continuation as an independent and well-developed country.
These problems include requirements of the growing water demands supply, clean energy production, and environmental preservation. One of the most difficult environmental problems is a continuous decrease in the Dead Sea level achieving closely to one meter per year. Such situation could cause its disappearance during the next 40-50 years. As well as the irreversible and very dangerous increase in salination of Mediterranean Sea water in the offshore zone because of intensive desalination of extracted seawater. Although the abovementioned problems seem independent, they are closely connected, and a comprehensive solution is desired.

Let us begin the analysis with growing energy demands. The most promising technologies in Israel for energy production are based on renewable sources, among which solar PV may provide the cheapest electricity considering Israel's annual irradiation. However, PV electricity is difficult to stabilize, may have rapid power fluctuations and is unavailable at night. Furthermore, if a surplus amount of PV electricity is being produced during daytime, its storage may only increase the cost of energy. According to published investigations, the maximum profitable share of $\mathrm{PV}$ production would not be more than $11-12 \%$ of overall energy production [1].

A promising solution for overcoming this limitation is massive low cost electrical storage. Currently, storage technologies (except pumping hydro-storage) are somewhat expensive and this is not likely to change in the foreseeable future [2]. Moreover, the exploitation of existing electrochemical, mechanical or special material solutions (superconductivity, for example) are not 
scalable to the required amounts [3-5]. However, the answer to these difficulties may be hybrid conjunction of solar PV production with pumped storage [6-9]. Pumped hydro-storage represents a promising solution yet for massive energy producing providing relatively cheap and reasonable electricity. The practical cost $2-3 \mathrm{c} / \mathrm{kWh}$ is pointed out as an achievable price of the electricity storage in hydro-pumped plants with $100 \mathrm{MW}$ and more of installed power. Owing to these advantages multiple application of hydro-pumped appliances for renewables applications were developed during the last 10-15 years. Despite the benefits of hydro-storage remain numerous queries regarding their effective use in real energy systems. Therefore, different techno-economical aspects of optimal cooperation between solar or others renewable electricity productions with hydro-pumped storage are analysed in [10-12]. Results of these investigations show promising possibilities for hydro-pumped storage in conjunction with renewable sources. However, the precise selection of storage characteristics and parameters should be carried out for effective application of such solutions.

The second of mentioned above problems is growing water requirements. Even without considering climate deterioration causing an increase in aridity in the Middle East, the need for water generation will grow rapidly. The promising solution may be sea water desalination [13-15]. It is emphasized the preferable use of reverse osmosis membranes among existing desalination technologies. Continuous improvement of this technology during the time caused to low water prices and high reliability of desalination plants. Fortunately, Israel has an inexhaustible source in the Mediterranean and Red seas. Therefore, desalination can be increased in Israel to nearly required level now and in the future. However, for the desalination process to be economical, it requires cheap electrical power which can be produced by solar or others renewable sources [16-18]. Moreover, brine as a by-product of the desalination having a high concentration of sea salts should be removed from the coastal area. However, for economic reasons, brine is preferably dumped close to shore. Significant amounts of brine in the eastern border of the Mediterranean offshore zone, which has very little mixing currents, will produce a permanent strongly saline area damaging flora and fauna of a sea. Considering mentioned above the production of a fresh water can be accompanied with a pumped hydro-storage that represents a promising solution for levelling energy demands [19]. For remind, turbines able to operate in sea and concentrated (brine) water already exist [20] and may be exploited in electric systems.

The third of the mentioned problems is the disappearance of the Dead Sea. The negative balance between water inflow and evaporation causes a permanent decrease in its level and an eventual disappearance, which will represent a catastrophic environmental change. The Dead Sea area produces unique climate and balneological conditions. Intensively evaporating water masses rise upwards and exert a positive influence on the entire climate of the adjacent area. It is impossible or extremely difficult to predict all the negative results if the Dead Sea will be lost. It should remain, and we must save it.

\section{Principle of the proposed solution.}

The solution includes the construction of a large amount of PV facilities in the Negev area as a majority coupled with other renewable power plants (wind, for example, or thermo-solar). A channel from the Mediterranean Sea to the Judean Heights area should be constructed with installation of desalination plants near the end of the channel and collecting pools for brine accumulation. Finally, cascaded hydropower electrical stations in the descent from the Judean heights to the Dead Sea for activating electrical turbines. The turbines of hydropower stations will apply the brine from the collecting pools for electricity production and will direct it after use to the Dead Sea. The principle scheme of the project is shown in Fig.1.

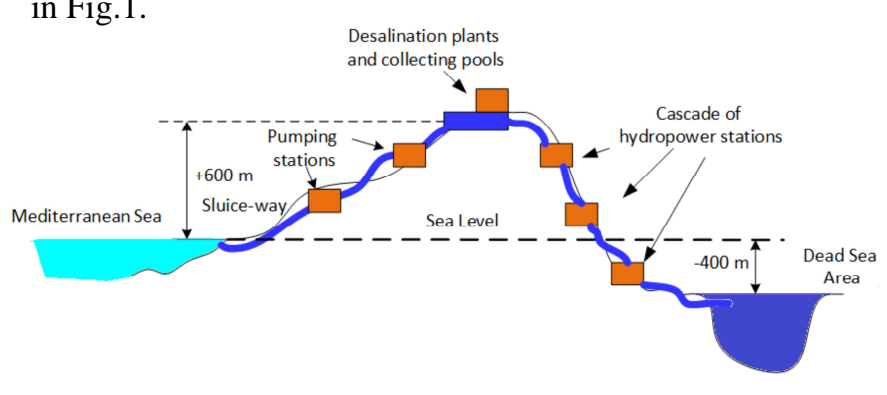

Fig.1. Principle scheme of the project frame

\section{A. Functioning of the project}

The PV plants will provide electricity to the Israeli main (together with others conventional power stations) and a surplus of a power to use for the pumping Mediterranean Sea water to the desalinating facilities and water purification. The fresh water will be used for the water supply and brine that will flow to the collecting pools and to the hydropower stations. Towards evening, the solar irradiation slows and eventually stops. This moment arrives close to the evening maximum of electricity demand when conventional plants are not able to supply all power needs; at this point the hydropower stations begin to work. They produce electricity to cover all power requirements together with conventional energy plants. Later, at night, hydropower stations will stop since electricity demand is much lower and the base capability of conventional electrical stations is enough to provide all energy needs.

A qualitative power-time diagram is represented in Fig.2. The diagram shows changing electricity demands (averaged for different seasons), baselines (maximum and minimum allowable levels of conventional electric plant power), PV facilities production (averaged for different seasons), hydropower functionality for shaving evening peak of power requirements, water pumping and desalination process. 


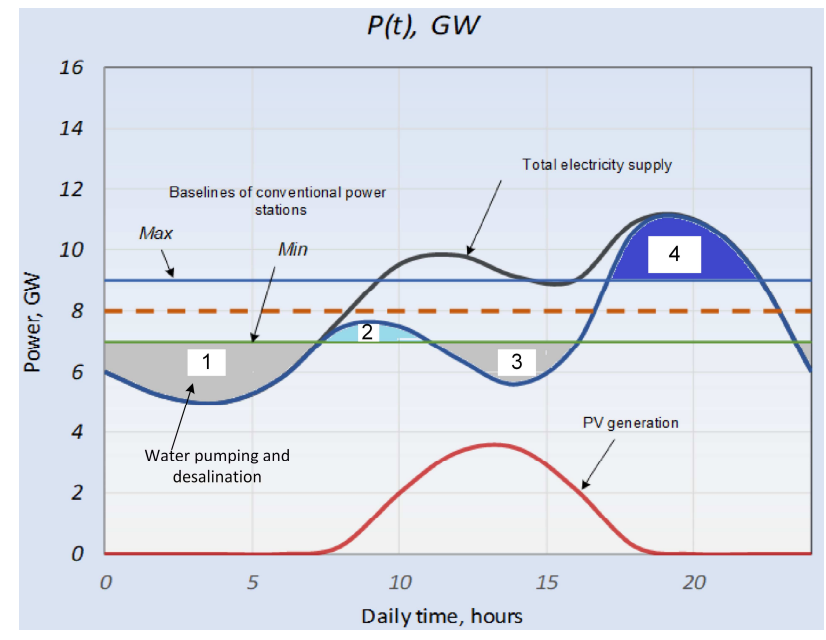

Fig.2. Principle power-time diagram of Israel energy system combining conventional power plants, PV generating facilities and hydropower stations.

The following is designated in Fig. 2:

1,3 - the process of water pumping and desalination due to surplus energy production;

2 - electricity supply from conventional power plant and PV facilities, without power surplus;

4 - hydropower stations functioning together with conventional stations.

\section{B. Major advantages of the project}

1. A solution to the fresh water supply for the future. Increased production of fresh water can be used to augment the Kinneret Sea and other national uses;

2. Possibility to establish new tourist areas surrounding pool zones of recreation and entertainment with parks and hotels, transforming significant areas of Judean Desert to green spaces;

3. Providing $20-25 \%$ and even more of total energy needs from renewable (mainly PV) sources;

4. Lower cost of electricity;

5. Total energy independence since the transformation to electrical transportation is imminent.

\section{Global estimations of potential project properties}

Firstly, the potential production of fresh water.

The amount of brine $\left(\mathrm{V}_{\text {brine }}\right)$ that could flow is equal to the evaporation of water from Dead Sea level (assuming constant sea level):

$$
V_{\text {brine }}=A \cdot h=650 \mathrm{~km}^{2} \cdot 1 \mathrm{~m}=650 \cdot 10^{6}, \mathrm{~m}^{3} / \text { year }
$$

The volume of Mediterranean Sea water should be pumped to the desalination plants (if Dead Sea level will be kept constant-):

$V_{\text {water }}=\frac{V_{\text {brine }}}{\left(1-K_{F W}\right)}=\frac{650 \cdot 10^{6}}{(1-0.3)} \approx(928 \div 929) \cdot 10^{6}, \mathrm{~m}^{3} /$ year

Where: $\mathrm{K}_{\mathrm{FW}}$-the coefficient of fresh water outcome from a sea water in desalination process, typically equal to 30 $40 \%$ at most.

The volume of fresh water and brine:

$$
\begin{aligned}
& V_{F W}=V_{\text {water }} \cdot 0.3=(278 \div 279) \cdot 10^{6}, \mathrm{~m}^{3} / \text { year } \\
& V_{\text {brine }}=V_{\text {water }} \cdot 0.7=(650 \div 651) \cdot 10^{6}, \mathrm{~m}^{3} / \text { year }
\end{aligned}
$$

Considering total fresh water demands [21] $2346 \cdot 10^{6}$ $\mathrm{m}^{3}$ per year that this project may provide (in constant Dead Sea level) $\sim 12 \%$ of total needs.

Estimation of daily water production:

$$
\begin{aligned}
& V_{\text {water }}^{*} ; 2.54 \cdot 10^{6}, \frac{\mathrm{m}^{3}}{\text { day }} \\
& V_{F W}^{*} ; 0.76 \cdot 10^{6}, \frac{\mathrm{m}^{3}}{\text { day }} \\
& V_{\text {brine }}^{*} ; 1.78 \cdot 10^{6}, \frac{\mathrm{m}^{3}}{\text { day }}
\end{aligned}
$$

The amount of electricity which can be obtained from the net brine discharge to the Dead Sea:

$$
\begin{aligned}
& E_{1 m}=\rho_{\text {brine }} \cdot H=\left(1.2 \cdot 10^{4} \mathrm{~N}\right) \cdot(400 \mathrm{~m})= \\
& =4.8 \cdot 10^{6} \mathrm{~J}=0.66 \div 0.67, \mathrm{kWh} \\
& E=V_{\text {brine }} \cdot\left(0.66 \div 0.67 \frac{\mathrm{kWh}}{\mathrm{m}^{3}}\right) \cdot \eta_{T}= \\
& \left((650 \div 651) \cdot 10^{6} \mathrm{~m}^{3}\right) \cdot\left(0.66 \div 0.67 \frac{\mathrm{kWh}}{\mathrm{m}^{3}}\right) \cdot(0.7 \div 0.8)= \\
& =(300 \div 349), \mathrm{GWh} / \text { year }
\end{aligned}
$$

Where:

$E_{1 \mathrm{~m}}$ - amount on energy from $1 \mathrm{~m}^{3}$ of brine flowing to Dead Sea from the Mediterranean Sea level to the Dead Sea, kWh;

$\mathrm{H}$-the net height of the water discharge, equal to $400 \mathrm{~m}$;

$\rho_{\text {brine }}$ - specific brine weight, $\mathrm{N} / \mathrm{m}^{3}$;

$\eta_{\mathrm{T}}$ - total efficiency of a water (brine) turbines, $0.7-0.8$ at minimum.

Annual (2016) amount of Israeli produced electricity was $67210 \mathrm{GWh}$ [22]. That is in a scenario when Dead Sea level remains constant, so from hydropower stations can be obtained $\sim 0.5 \%$ of the total needs. If the level of Dead Sea can be assumed rising $1 \mathrm{~m} /$ year, the amount of electricity production may achieve $\sim 1 \%$ of the entire requirements. An increase in the level of $1 \mathrm{~m}$ per year is quite acceptable. With such an increase, the level of the dead sea in 50 years will return to that which was before intensive use of sea minerals and decrease of water income from Jordan river in the middle of the previous century.

A significantly bigger profit in electricity production can be obtained from the pumping energy storage, which ensures levelling of PV and power from other renewable plants. This scenario can provide much more electricity: 
$E_{\text {year }}=W_{1 m} \cdot V_{\text {brine/year }} \cdot \frac{H^{+}}{H^{-}} \cdot \eta_{T}=$

$=(0.66 \div 0.67) \cdot\left((650 \div 651) \cdot 10^{6}\right) \cdot \frac{600}{400} \cdot(0.7 \div 0.8) \approx$

$488, G W h /$ year

$E_{\text {day }}=\frac{488}{365} \approx 1.33, G W h /$ day

Where: $\mathrm{H}^{+}, \mathrm{H}^{-}$- are a positive height of a sea water pumping and a brine water fall down, $\mathrm{m}$.

Since evening maximum of electricity supply $\sim 12 \mathrm{GW}$ and its duration of $\sim 0.9-1$-hour, hydropower stations can shave up to $11-12 \%$ of this peak, which is very significant. However, this will require the total hydropower station to provide 1.3-1.4 GW of power.

Total average power and installation capacitance of PV plant (only for the pumping requirements):

$$
\begin{aligned}
& E_{\text {pump }}=\frac{V \cdot \rho \cdot H}{\eta_{\text {pump }}}=\frac{\left(2.54 \cdot 10^{6} \mathrm{~m}^{3}\right) \cdot\left(1.05 \cdot 10^{4} \frac{\mathrm{N}}{\mathrm{m}^{3}}\right) \cdot(600 \mathrm{~m})}{0.8}= \\
& =2000 \cdot 10^{10}, \mathrm{~J}=5.56, \mathrm{GWh} / \text { day }
\end{aligned}
$$

Considering that $1 \mathrm{~W}$ of nominal PV power produces 4.5 Wh per day [23], installed power of PV plants (only for pumping needs):

$$
\left(P_{\text {pump }}\right)_{a v}=\frac{5.56}{4.5}=1.24, G W
$$

In addition, PV power may be used for the daytime electricity supply. The estimation can be carried out assuming some flexibility factor (FF) value of a conventional electrical system that is equal to the economically reasonable ratio of minimum-maximum powers. FF can be assessed as a ratio of daytime to evening peaks which is equal to $F F=\frac{9 G W}{12 G W}=0.75$ for Israel electrical system. Considering that evening peak can be reduced by $11-12 \%$ due to the use of hydropower stations the additional PV plants power may be equal to:

$$
\left(P_{P V}\right)_{\text {add }}=9-12 \cdot 0.89 \cdot 0.75 ; 1.0, G W
$$

And totally it will ensure $\sim 2.3 \mathrm{GW}$ of allowable PV plant power. Virtual FF of Israel electric system may achieve lower values, say $0.65-0.7$. In this case additional PV stations may have more economically proved power.

In this estimation, future energy needs for electrical transportation were not considered. Obviously, the electricity supply of electrical transportation can increase the need for PV station power. More comprehensive analysis and a deeper project of real possibilities to create $\mathrm{PV}$ and other renewable plants can be evaluated in future research.

\section{Conclusions}

1. Calculated results show a significant synergistic efficiency of the entire project that will include Mediterranean-Dead Sea channel, desalination plants, brine collecting pools and a cascade of hydropower stations on the descent from Judea Heights to the Dead Sea.

2. The project may provide minimum $12 \%$ of water requirements (if Dead Sea level will remain constant) and up to $24-25 \%$ if it will be allowed to rise by $\sim 1 \mathrm{~m} /$ year.

3. Electricity production from hydropower station may cover $\sim 1 \%$ of total needs only. However, much more important are the levelling of evening power demands comprising $\sim 11-12 \%$ at a minimum. If sea level will rise $\sim 1 \mathrm{~m}$ /year, peaks levelling would be more in accordance.

4. Considering the results of the given estimation of total installed PV plants power may achieve 2.3-2.5 $\mathrm{GW}$ at a minimum. Allowing the rise of the Dead Sea level and gradual introduction of electrified transportation will permit much more PV power.

5. The estimation should be improved to more significant values of water and electricity permitted amounts since during the Dead Sea level rising its area will increase and an evaporation process, as a result, will be intensified.

6. All assessments should be corrected if the Dead Sea level will rise gradually. In this scenario, the obtained results need to be multiplied accordingly.

7. The continuation of the proposed research is being planned in the present time. It should include the detailed analysis of techno-economical aspects of a channel route, locations and sizing evaluations of desalination plants, hydro-power station and PV plants.

8. A significant improvement in the overall economic situation and the decrease of political tension in the region can be expected with the implementation of this project owing to enlarged water and energy production.

\section{Acknowledgement}

0Authors express deep gratitude and special thanks to Mr. Larry Loev for his generous assistance in improving the text and helpful discussions.

\section{References}

[1] A Solomon, DM Kammen, D Callaway. Investigating the impact of wind-solar complementarities on energy storage requirement and the corresponding supply reliability criteria, Appl.Energy. 168 (2016) 130-145.

[2] X Luo, J Wang, M Dooner, J Clarke. Overview of current development in electrical energy storage technologies and the application potential in power system operation, Appl.Energy. 137 (2015) 511-536. 
[3] D Akinyele, $\mathrm{R}$ Rayudu. Review of energy storage technologies for sustainable power networks, Sustainable Energy Technologies and Assessments. 8 (2014) 74-91.

[4] Azzuni and C. Breyer, "Energy security and energy storage technologies," Energy Procedia, vol. 155, pp. 237-258, November 20182018.

[5] M.Z. Jacobson, M.A. Delucchi, M.A. Cameron and B.A. Frew, "Low-cost solution to the grid reliability problem with $100 \%$ penetration of intermittent wind, water, and solar for all purposes," Proc.Natl.Acad.Sci.U.S.A., vol. 112, no. 49, pp. 15060-15065, Dec 82015.

[6] M.Z. Jacobson and M.A. Delucchi, "Providing all global energy with wind, water, and solar power, part I: Technologies, energy resources, quantities and areas of infrastructure, and materials," Energy Policy, vol. 39, no. 3, pp. 1154-1169, March 20112011.

[7] M. Aliyu, G. Hassan, S.A. Said, M.U. Siddiqui, A.T. Alawami and I.M. Elamin, "A review of solar-powered water pumping systems," Renewable and Sustainable Energy Reviews, vol. 87, pp. 61-76, May 20182018.

[8] V.C. Sontake and V.R. Kalamkar, "Solar photovoltaic water pumping system - A comprehensive review," Renewable and Sustainable Energy Reviews, vol. 59, pp. 1038-1067, June 20162016.

[9] T. Ma, H. Yang and L. Lu, "Feasibility study and economic analysis of pumped hydro storage and battery storage for a renewable energy powered island," Energy Conversion and Management, vol. 79, pp. 387-397, March 20142014.

[10] W. Fang, Q. Huang, S. Huang, J. Yang, E. Meng and Y. Li, "Optimal sizing of utility-scale photovoltaic power generation complementarily operating with hydropower: A case study of the world's largest hydro-photovoltaic plant," Energy Conversion and Management, vol. 136, pp. 161-172, 15 March 20172017.

[11] Ming, P. Liu, S. Guo, X. Zhang, M. Feng and X. Wang, "Optimizing utility-scale photovoltaic power generation for integration into a hydropower reservoir by incorporating long- and short-term operational decisions," Applied Energy, vol. 204, pp. 432-445, 15 October 20172017.

[12] T. Ma, H. Yang, L. Lu and J. Peng, "An optimization sizing model for solar photovoltaic power generation system with pumped storage," Energy Procedia, vol. 61, pp. 5-8, 2014 2014

[13] A Cipollina, G Micale, L Rizzuti, Seawater desalination: conventional and renewable energy processes, Springer Science \& Business Media 2009.

[14] E Chafik. A new type of seawater desalination plants using solar energy, Desalination. 156 (2003) 333-348.

[15] WG Shim, K He, S Gray, IS Moon. Solar energy assisted direct contact membrane distillation (DCMD) process for seawater desalination, Separation and Purification Technology. 143 (2015) 94-104.

[16] L Perković, T Novosel, T Pukšec, B Ćosić, M Mustafa, G Krajačić, et al. Modeling of optimal energy flows for systems with close integration of sea water desalination and renewable energy sources: Case study for Jordan, Energy conversion and management. 110 (2016) 249-259.

[17] A. Al-Karaghouli and L.L. Kazmerski, "Energy consumption and water production cost of conventional and renewableenergy-powered desalination processes," Renewable and Sustainable Energy Reviews, vol. 24, pp. 343-356 2013.

[18] E. Tzen and R. Morris, "Renewable energy sources for desalination," Solar Energy, vol. 75, no. 5, pp. 375-379 2003.
[19] S Rehman, LM Al-Hadhrami, MM Alam. Pumped hydro energy storage system: A technological review, Renewable and Sustainable Energy Reviews. 44 (2015) 586-598.

[20] L. Chen and W. Lam, "A review of survivability and remedial actions of tidal current turbines," Renewable and Sustainable Energy Reviews, vol. 43, pp. 891-900 2015.

[21] https://www.knesset.gov.il/mmm/data/pdf/m04205.pdf

[22] http://www.cbs.gov.il/reader/?MIval=cw_usr_view_SHTM $\mathrm{L} \& \mathrm{ID}=561$

[23] D. Faiman, D. Feuermann, P. Ibbetson, B. Medwed, A. Zemel, A. Ianetz, V. Liubansky, I. Setter and S. Suraqui, "The negev radiation survey," Journal of solar energy engineering, vol. 126, no. 3, pp. 906-914 2004. 